\title{
Economic and humanistic burden of illness in generalized anxiety disorder: an analysis of patient survey data in Europe
}

This article was published in the following Dove Press journal:

ClinicoEconomics and Outcomes Research

2 April 2014

Number of times this article has been viewed

\author{
Samira Toghanian' \\ Marco DiBonaventura ${ }^{2}$ \\ Krister Järbrink' \\ Julie C Locklear ${ }^{3}$
}

'AstraZeneca R\&D, Mölndal, Sweden; ${ }^{2}$ Kantar Health, New York, NY, USA;

${ }^{3}$ AstraZeneca Pharmaceuticals,

Wilmington, DE, USA
Correspondence: Marco DiBonaventura Health Outcomes Practice, Kantar Health, II Madison Avenue, 12th Floor, New York, NY I00I0, USA

$\mathrm{Tel}+$ I 2127063988

Fax +I 2126477659

Email marco.dibonaventura@

kantarhealth.com
Background: Whilst studies suggest that generalized anxiety disorder (GAD) represents a considerable health care burden in Europe, there is a paucity of published evidence. This study investigated the burden of illness associated with GAD across five European countries (France, Germany, Italy, Spain, and the UK).

Methods: Information from the 2008 European National Health and Wellness Survey database was analyzed. Bivariate, multivariate, and cost analyses were used to compare patients with GAD and propensity-matched controls.

Results: Compared with non-GAD controls, patients with GAD had more comorbidities and were more likely to smoke but less likely to be employed, use alcohol, or take exercise. They also had significantly worse health-related quality of life, and significantly greater work impairment and resource use, which increased as GAD severity increased. Within-country analyses demonstrated results similar to those for the five European countries overall, with the largest differences in resource use between patients with GAD and non-GAD controls documented in France and Germany. The average mean differences in direct costs were relatively small between the GAD groups and controls; however, indirect costs differed substantially. Costs were particularly high in Germany, mainly due to higher salaries leading to higher costs associated with absence from work. The limitation of this study was that the data were from a self-reported Internet survey, making them subject to reporting bias and possibly sample bias.

Conclusion: Across all five European countries, GAD had a significant impact on work impairment, resource use, and economic costs, representing a considerable individual and financial burden that increased with severity of disease. These data may help us to understand better the burden and costs associated with GAD.

Keywords: generalized anxiety disorder, Europe, economic burden, burden of illness

\section{Introduction}

Generalized anxiety disorder (GAD) is a disabling psychiatric illness characterized by excessive worry, without specific cause, for a period of at least 6 months. ${ }^{1}$ GAD is often a chronic condition and is associated with reduced health-related quality of life (HRQoL) and psychosocial functioning, low overall life satisfaction, and impairment in the ability to fulfill roles and social tasks. ${ }^{2}$ GAD is twice as common in women as in men $^{3,4}$ and is often comorbid with other psychiatric disorders and/or medical conditions. ${ }^{5-9}$ Considerable variability in prevalence has been observed between European countries; ${ }^{10,11}$ however, in Europe overall, the 12-month prevalence of GAD is estimated to be approximately $2 \%$ of the adult population, ${ }^{12}$ with higher rates $(5.3 \%)$ reported for patients receiving treatment in the primary care setting. ${ }^{13}$ 
Current guidelines for the pharmacological treatment of patients with GAD recommend antidepressants, such as selective serotonin reuptake inhibitors and selective noradrenaline reuptake inhibitors, pregabalin, benzodiazepines, buspirone, and tricyclic antidepressants. ${ }^{14}$

Previous studies suggest that GAD represents a considerable individual and societal health care burden in Europe. ${ }^{13,15-20}$ In a study of 1,042 patients, comorbidity and severity of symptoms were found to contribute toward cost of caring for patients with GAD. ${ }^{19}$ Loss of productivity and hospitalizations were the two most important contributors toward cost of care, both in patients with comorbidities and those without; however, most aspects contributing to cost were higher where comorbidities existed. Wittchen et al performed a survey of 558 primary care physicians alongside diagnostic screening of more than 20,000 patients for GAD. ${ }^{13}$ High utilization of health care resources was observed in patients with GAD, and this was even more extreme when GAD was comorbid with depression. The functional health of 20,921 study participants in a UK resident population was assessed using the Medical Outcomes Study Short Form-36 questionnaire and independent selfcompleted questionnaires. ${ }^{20}$ It was found that physical functional impairment of depression and anxiety has an impact on the patients' health that is independent of that caused by chronic medical illness. Indeed, chronic anxiety was shown to be associated with a detrimental impact on physical health greater than that seen with many chronic physical conditions. Reviews of the available literature on the human and economic impact of GAD on patients and health care systems have been performed, and comparisons made with the burden of other conditions. ${ }^{16,18}$ The literature showed that HRQoL impairment with GAD was comparable with and often greater than that of other anxiety disorders and some physical conditions. These reviews also showed that impairment of GAD was similar to that of major depressive disorder, and that lost work productivity and high medical resource use meant that GAD was associated with considerable economic cost. However, despite the prevalence of this disorder, there is a paucity of published evidence estimating the economic and humanistic burden of illness in patients with GAD, especially in Europe. ${ }^{15}$

This study investigates the demographics, disease characteristics, impact on HRQoL, work productivity, health care resource utilization, and cost burden of GAD across five European countries (France, Germany, Italy, Spain, and the UK). It aims to help us to better understand and define the burden and costs associated with this chronic anxiety disorder.

\section{Materials and methods Study design}

This was an analysis of data drawn from the European (France, Germany, Italy, Spain, and the UK) National Health and Wellness Survey database for 2008 (database described in detail in Langley et al). ${ }^{21}$ The survey was conducted by Kantar Health (New York, NY, USA). The database captures information via a self-administered Internet-based questionnaire that is stratified by sex and age to represent the demographic composition of the European adult population $(\geq 18$ years). Each respondent was permitted to participate once in the study. The database included self-declared information on GAD diagnosis and severity (assessed on a three-point graded scale of mild, moderate, or severe), demographics, comorbid conditions, health habits, treatments, medication use, health care resource utilization, work productivity, and activity impairment.

\section{Patients}

All participants who self-declared a GAD diagnosis were eligible for inclusion in the GAD cohort. Respondents not diagnosed with GAD were eligible for the non-GAD control group. In order to prevent overestimation of the costs for GAD, the control group also included patients with comorbid non-GAD anxiety. Each patient with GAD was propensity matched with a non-GAD control based on country of origin, age, sex, and employment status. All respondents in the National Health and Wellness Survey database provided informed consent electronically prior to answering any survey questions. Because the survey was administered entirely online, written consent was not possible. All electronic forms of consent were saved and stored in association with each respondent's unique identifier. All respondents were only known by this unique identifier. The survey and procedure were approved by an institutional review board (Essex Institutional Review Board, Lebanon, NJ, USA).

\section{Assessments}

\section{Demographics and disease characteristics}

Demographic information (including age, sex, marital status, income, and employment) as well as general patient and disease characteristics (including comorbidity count, alcohol use, exercise, smoking behavior, and disease severity) were compared between patients with GAD and nonGAD controls. 


\section{HRQoL}

HRQoL data were collected for patients with GAD and non-GAD controls using the Short Form-12 Health Survey Version $2^{22}$ and are presented in terms of physical component summary (PCS) and mental health component summary (MCS) scores (lower scores representing greater HRQoL impairment).

\section{Work productivity}

Productivity at work was assessed for GAD respondents and non-GAD controls using four subscales of the Work Productivity and Activity Impairment questionnaire (absenteeism, presenteeism, overall work impairment, and activity impairment). ${ }^{23}$ The four subscales are scored as percentages, with higher values indicating greater impairment.

The number of hours absent from work was captured by the questionnaire and absenteeism was calculated by dividing the number of work hours missed due to health problems in the past 7 days by the number of work hours missed due to health problems plus the number of hours actually worked in the past 7 days.

Presenteeism is a percentage rating that represents the level of productivity lost due to health problems. Number of work hours lost due to reduced productivity while at work was calculated by dividing reduced productivity while at work by 10 , multiplied by hours actually worked.

Overall work impairment is absenteeism plus nonabsenteeism (100\% minus absenteeism) multiplied by presenteeism. These three subscales (absenteeism, presenteeism, and overall work impairment) were only assessed for those who were full-time or part-time employed or self-employed.

Activity impairment is a percentage rating that represents the degree to which health problems affect regular activities. This item was assessed for all respondents.

\section{Health care resource utilization}

Data on the number of physician visits, psychiatrist/ psychologist visits, visits to other traditional health care providers, visits to nontraditional health care providers, hospitalizations, emergency room visits, and total number of medications were compared between patients with GAD and non-GAD controls.

\section{Cost burden}

Cost analyses were conducted at an individual patient level to determine the health care costs (both direct and indirect) associated with patients with GAD and non-GAD controls.
Direct medical cost evaluations included GAD medications, emergency room visits, hospitalizations, psychiatrist/psychologist visits, and general practitioner/ family practitioner visits. Indirect costs included those associated with absenteeism and presenteeism. GAD medication costs (in Euros) for each country were obtained through the Information Management System (MDART database).

\section{Statistical analysis}

Bivariate analyses were conducted to examine whether or not there was a difference between patients with GAD and nonGAD controls for demographics, patient characteristics, work productivity impairment, and resource use. Bivariate analyses were also used to examine the interrelationships between severity, patient segments, HRQoL, resource use, and work impairment. Differences between the groups for continuous dependent variables were analyzed using independent sample Student's $t$-tests. For categorical dependent variables, chisquared tests were used. Cohen's $d$ (for continuous variables) and the phi coefficient ( $\varphi$; for categorical variables) were used as measures of effect size.

Multivariate analyses were conducted to better understand the relationships between GAD disease severity, work productivity loss, and resource use in the overall population of patients with GAD compared with non-GAD controls. For the analysis of work productivity metrics, a series of generalized linear models specifying a negative binomial distribution with group variable (GAD versus non-GAD control) as the primary independent variable were used to predict absenteeism, presenteeism, overall work impairment, and activity impairment. This technique was used as all the mentioned outcomes were non-normally distributed. Covariates were age, sex, marital status, household income, education, health insurance, alcohol use, smoking, exercise behavior, and comorbidity count.

To analyze health care resource use, logistic regression models using GAD versus non-GAD controls predicted the likelihood of the dichotomous visit outcomes (yes or no to visit). To examine differences between the GAD group and the non-GAD control group on the number of (traditional) health care visits, number of emergency room visits, number of hospitalizations, and total number of medications, a series of generalized linear models were conducted. The generalized linear models specified a negative binomial distribution because these variables represent counts and the distributions were highly skewed.

The following covariates were controlled for in all multivariate analyses: age, sex, marital status, household 
income, education, health insurance, alcohol use, smoking, exercise behavior, and comorbidity count. An assessment of the tolerance and variance inflation factor was performed to ensure there were no issues of potential multicollinearity. Indeed, all of these covariates had tolerance values of at least 0.37 (a value of less than 0.20 would indicate potential multicollinearity) and variance inflation factor values of less than 2.7 (values of more than 5 would indicate potential multicollinearity). All multivariate data are presented as rate ratios, which give the ratio of the mean values for GAD patients versus non-GAD controls.

Costs are presented descriptively across all five countries (pooled analyses) and for each country individually. Short Form-6D scores ${ }^{24}$ were used to derive HRQoL utilities and to estimate the economic impact any improvement in HRQoL would have on direct, indirect, and total costs, ie, to estimate the Euro change for each 0.01 increase in HRQoL utility score. Omega-squared $\left(\omega^{2}\right)$ was calculated as a measure of effect size.

\section{Results \\ Patients}

Of 53,524 respondents, 3,669 self-declared a diagnosis of GAD and were propensity-matched 1:1 to a control group without a declared GAD diagnosis.

\section{Demographics and disease characteristics}

Across all five European countries, patients with GAD had significantly higher comorbidities for a range of individual conditions and were less likely to be employed than non-GAD controls. They were also more likely to smoke and less likely to use alcohol and take exercise (Table 1).

Comparisons between patients with GAD and controls within each European country showed that the pattern of results was generally the same as that described for the overall pooled analysis. However, in Italy, there were no demographic differences between patients with GAD and non-GAD controls, and the differences between the groups in terms of health behavior (alcohol use, exercise, smoking) were more modest in Italy, Germany, and France than in Spain and the UK (see Supplementary Table 1).

\section{HRQoL}

The HRQoL of patients with GAD in Europe was poorer than that of the non-GAD control group; respondents with GAD reported significantly lower mean \pm standard deviation PCS scores (45.6 \pm 11.6 versus non-GAD controls 48.2 \pm 11.0 ; $P<0.001)$ and MCS scores $(34.9 \pm 10.6$ versus $45.5 \pm 10.8$, respectively; $P<0.001$, Table 1). PCS and MCS scores were also significantly lower for patients with GAD versus non-GAD controls in each individual country (see Supplementary Table 2). As GAD severity increased, HRQoL decreased significantly $(P<0.05)$ across all five European countries, ie, the differences in MCS and PCS scores between patients with GAD versus non-GAD controls increased as GAD severity increased.

\section{Work productivity}

Figure 1 presents the results of the multivariate analysis of work productivity as rate ratios (ratios of the mean scores for patients with GAD versus non-GAD controls). In Europe overall, patients with GAD had significantly higher mean levels of absenteeism, presenteeism, overall work impairment, and activity impairment than the non-GAD control group. The rate ratio for patients with GAD versus non-GAD controls for absenteeism in Europe overall was 1.59, which indicates a $59 \%$ higher mean value for patients with GAD versus non-GAD controls. The rate ratios for presenteeism, overall work impairment, and activity impairment in Europe overall were 1.33, 1.38, and 1.16, respectively (Figure 1).

In France and Germany, work impairment and activity impairment were higher in patients with GAD compared with controls, although both groups in Germany had similar levels of absenteeism. Patients with GAD in Spain had higher levels of absenteeism and overall work impairment, and patients with GAD in Italy had higher levels of activity impairment compared with non-GAD controls. In the UK, levels of work and activity impairment were similar in the two groups.

Across all five European countries, absenteeism was not significantly higher for patients with mild GAD compared with the control group; however, the differences in absenteeism between patients with GAD versus non-GAD controls were significantly higher $(P<0.0001)$ for patients with moderate and severe GAD.

\section{Health care resource utilization}

In Europe, patients with GAD were significantly more likely to visit traditional and nontraditional health care providers than the non-GAD control group (Figure 2A). The rate ratios for patients with GAD versus non-GAD controls in Europe overall were 1.71 for the likelihood of visits to a traditional health care provider and 1.22 for the likelihood of visits to a nontraditional health care provider.

Patients with GAD had a higher number of total visits to a traditional health care provider, a general practitioner/ family practitioner, or psychiatrist/psychologist, and received a higher number of total medications versus non-GAD 
Table I Patient demographics, disease characteristics, and health status

\begin{tabular}{|c|c|c|c|c|c|}
\hline $\begin{array}{l}\text { Demographics, disease } \\
\text { characteristics, and health } \\
\text { status }\end{array}$ & $\begin{array}{l}\text { GAD patients } \\
\mathrm{n}=3,669\end{array}$ & $\begin{array}{l}\text { Non-GAD controls } \\
n=3,669\end{array}$ & Cohen's $d / \varphi$ & $t / \chi^{2}$ & $P$-value \\
\hline Age, years & & & 0.06 & -2.44 & 0.015 \\
\hline Mean \pm SD & $46.49 \pm 13.48$ & $45.72 \pm 13.48$ & & & \\
\hline Mean $(95 \% \mathrm{Cl})$ & $46.49(46.05-46.93)$ & $45.72(45.29-46.16)$ & & & \\
\hline Median (range) & $47.00(18.00-82.00)$ & $47.00(18.00-86.00)$ & & & \\
\hline Sex, n (\%) & & & 0.00 & 0.01 & $0.94 I$ \\
\hline Male & $\mathrm{I}, 245(33.9)$ & $\mathrm{I}, 242(33.9)$ & & & \\
\hline Female & $2,424(66.1)$ & $2,427(66.1)$ & & & \\
\hline Married, n (\%) & & & -0.02 & 3.49 & 0.062 \\
\hline Not married & I,928 (52.5) & $\mathrm{I}, 848(50.4)$ & & & \\
\hline Married & $\mathrm{I}, 74 \mathrm{I}(47.5)$ & $\mathrm{I}, 82 \mathrm{I}(49.6)$ & & & \\
\hline Employment, n (\%) & & & 0.07 & 38.70 & $<0.001$ \\
\hline Employed & I,97I (53.7) & $2,195(59.8)$ & & & \\
\hline Retired & $130(3.5)$ & $155(4.2)$ & & & \\
\hline On disability & $298(8.1)$ & $285(7.8)$ & & & \\
\hline Other & $\mathrm{I}, 270(34.6)$ & $\mathrm{I}, 034(28.2)$ & & & \\
\hline Alcohol, n (\%) & & & -0.03 & 7.42 & 0.006 \\
\hline Do not drink alcohol & $940(25.6)$ & $840(22.9)$ & & & \\
\hline Drink alcohol & $2,729(74.4)$ & $2,829(77.1)$ & & & \\
\hline Smoking, n (\%) & & & 0.07 & 35.87 & $<0.001$ \\
\hline Do not smoke & $2,301(62.7)$ & $2,544(69.3)$ & & & \\
\hline Currently smoke & I,368 (37.3) & $\mathrm{I}, 125(30.7)$ & & & \\
\hline Exercise per month, days & & & 0.05 & 2.16 & 0.031 \\
\hline Mean \pm SD & $5.35 \pm 7.59$ & $5.74 \pm 7.97$ & & & \\
\hline Mean $(95 \% \mathrm{Cl})$ & $5.35(5.10-5.59)$ & $5.74(5.48-6.00)$ & & & \\
\hline Median (range) & $1.00(0.00-31.00)$ & $2.00(0.00-31.00)$ & & & \\
\hline Comorbidity count & & & 1.20 & -51.17 & $<0.001$ \\
\hline Mean \pm SD & $10.68 \pm 5.37$ & $4.93 \pm 4.17$ & & & \\
\hline Mean $(95 \% \mathrm{Cl})$ & $10.68(10.50-10.85)$ & $4.93(4.80-5.07)$ & & & \\
\hline Median (range) & $10.00(2.00-94.00)$ & $4.00(0.00-34.00)$ & & & \\
\hline MCS score ${ }^{22}$ & & & 0.99 & 42.56 & $<0.001$ \\
\hline Mean \pm SD & $34.89 \pm|0.6|$ & $45.53 \pm|0.8|$ & & & \\
\hline Mean $(95 \% \mathrm{Cl})$ & $34.89(34.54-35.23)$ & $45.53(45.18-45.88)$ & & & \\
\hline Median (range) & $34.87(0.60-69.16)$ & $46.56(6.26-77.09)$ & & & \\
\hline PCS score ${ }^{22}$ & & & 0.23 & 9.73 & $<0.001$ \\
\hline Mean \pm SD & $45.62 \pm I 1.60$ & $48.19 \pm 10.96$ & & & \\
\hline Mean $(95 \% \mathrm{Cl})$ & $45.62(45.25-46.00)$ & $48.19(47.83-48.54)$ & & & \\
\hline Median (range) & $47.48(8.60-71.09)$ & $51.29(6.27-70.98)$ & & & \\
\hline Health utilities score ${ }^{24}$ & & & 1.00 & 37.52 & $<0.001$ \\
\hline Mean \pm SD & $0.61 \pm 0.10$ & $0.7 I \pm 0.13$ & & & \\
\hline Mean $(95 \% \mathrm{Cl})$ & $0.6 \mathrm{I}(0.6 \mathrm{I}-0.6 \mathrm{I})$ & $0.7 \mathrm{I}(0.7 \mathrm{I}-0.72)$ & & & \\
\hline Median (range) & $0.62(0.35-1.00)$ & $0.66(0.35-1.00)$ & & & \\
\hline
\end{tabular}

Notes: Patient population comprised patients with a diagnosis of GAD and non-GAD controls from France, Germany, Italy, Spain, and the UK. Control group had no specific GAD diagnosis (self-report) but could have reported another anxiety disorder (eg, social anxiety disorder, panic disorder). Cohen's $d$ (for continuous variables) and the phi coefficient ( $\varphi$, for categorical variables) were used as measures of effect size.

Abbreviations: $\mathrm{Cl}$, confidence interval; GAD, generalized anxiety disorder; MCS, mental health component summary; PCS, physical component summary; SD, standard deviation.

controls, although there were no differences between the groups in mean number of emergency room visits or number of hospitalizations (Figure 2B).

Within-country comparisons of health care resource utilization varied considerably. However, in general, compared with non-GAD controls, patients with GAD were significantly more likely to visit a traditional health care provider in France, Spain, and the UK, and significantly more likely to visit nontraditional health care providers in France and Italy (Figure 2A).
In Germany, patients with GAD appeared to have a lower likelihood of visiting traditional and nontraditional health care providers than non-GAD controls, although the difference between the two groups was not statistically significant, which suggests a degree of variability. However, the actual number of health care visits to a traditional health care provider was higher in Germany for patients with GAD compared with non-GAD controls. This was also true for France and Italy (Figure 2B). The difference in number of actual general practitioner/family 


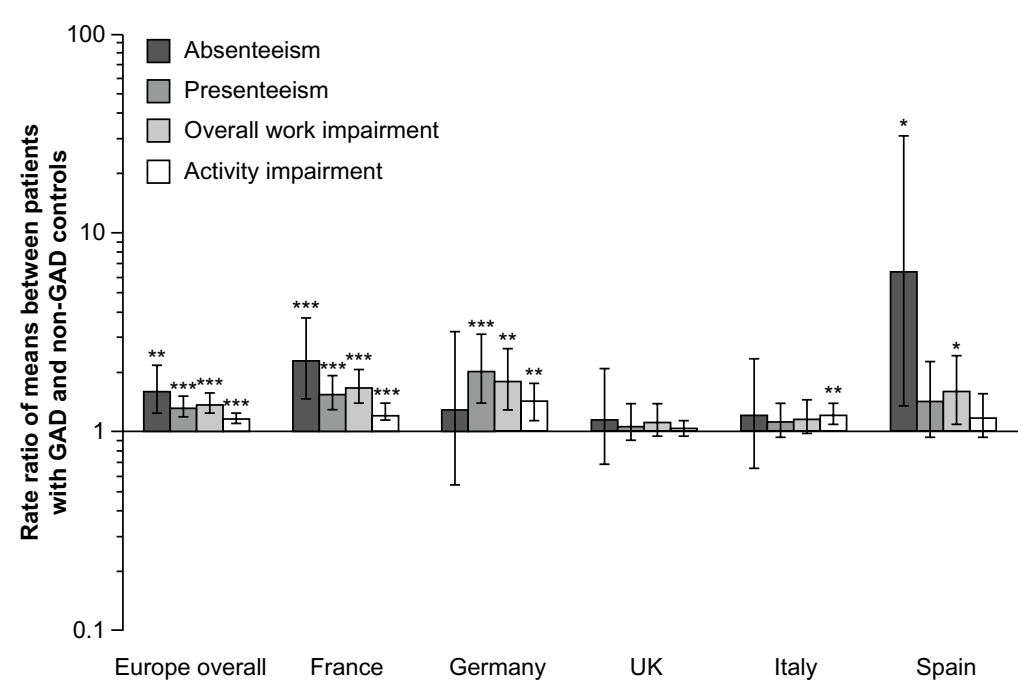

Figure I Impairment in work productivity and daily activities in patients with GAD.

Notes: $* P<0.05 ; * * P<0.0$ I; $* * * P<0.00$ I GAD patients versus non-GAD controls. Rate ratio $>$ I indicates the mean value for GAD patients is higher than for non-GAD controls. Europe overall refers to the five European countries included in this study.

Data from across five European countries (France, Germany, Italy, Spain, and the UK) and within each country.

Abbreviation: GAD, generalized anxiety disorder.

practitioner visits between patients with GAD and controls was significant in France and the UK. In the UK, the number of other traditional health care provider visits (nonpsychiatrist/ psychologist and nongeneral practitioner/family practitioner) was actually significantly lower for patients with GAD than non-GAD controls. In all other countries, there were no significant differences between groups for number of other traditional health care provider visits. UK patients with GAD also reported significantly fewer emergency room visits than non-GAD controls, while in Spain patients with GAD reported significantly more emergency room visits.

UK patients with GAD reported using a significantly lower total number of medications versus non-GAD controls; although in all other countries (with the exception of Spain, where the difference was not statistically significant) patients with GAD used a significantly higher number of medications (Figure 2B). In no country were there significant differences in total number of hospitalizations between patients with GAD and non-GAD controls.

For most GAD patients, levels of resource use increased as GAD severity increased. However, for most patients, only those with severe GAD had significantly more psychologist/ psychiatrist visits than control groups (mild and moderate patients did not differ from controls).

\section{Cost burden}

Across all five European countries, direct costs were on average $€ 659$ (95\% confidence interval [CI] 534-785) and indirect costs were $€ 2,208$ (95\% CI 1,900-2,517) higher per patient per year for those with GAD versus non-GAD controls
(Table 2). Direct cost differences were driven by hospitalizations and visits to psychologist/psychiatrists.

The costs of GAD were particularly high in Germany, although the number of hours of productivity loss was comparable across countries. High median salaries in Germany resulted in direct costs that were $€ 2,406$ (95\% CI 1,182-3,631) higher and indirect costs that were $€ 5,515(95 \%$ CI $3,078-7,952)$ higher for GAD versus non-GAD controls (Figure 3 ).

Multivariate analyses demonstrated that as GAD severity increased, total costs also increased across all five countries and also for individual countries (Figure 4). The total cost for patients with mild GAD was $€ 3,833$ (95\% CI 3,554-4,112), for moderate GAD was $€ 5,561$ (95\% CI 5,142-5,981), and for severe GAD was $€ 7,451(95 \%$ CI 6,411-8,491). Patients without GAD had a total cost of $€ 2,167$ (95\% CI 1,965-2,370).

Although Germany had the highest costs overall, patients with severe GAD ( $€ 9,900$ [95\% CI 5,887-13,914]) actually had lower costs than patients with moderate $(€ 13,546$ [95\% CI 10,359-16,733]) GAD. Patients with severe GAD in France, the UK, and Italy were comparable in their total costs (relative to non-GAD control groups), although patients with severe GAD in Spain had the largest difference in costs relative to non-GAD controls ( $€ 8,922$ [95\% CI 3,736-14,108] versus $€ 1,748$ [1,226-2,270], respectively).

Improvements in HRQoL among patients with GAD predicted a significantly greater decrease in costs than for non-GAD controls (Table 3). In general, improving HRQoL would have the most dramatic impact on indirect costs. 

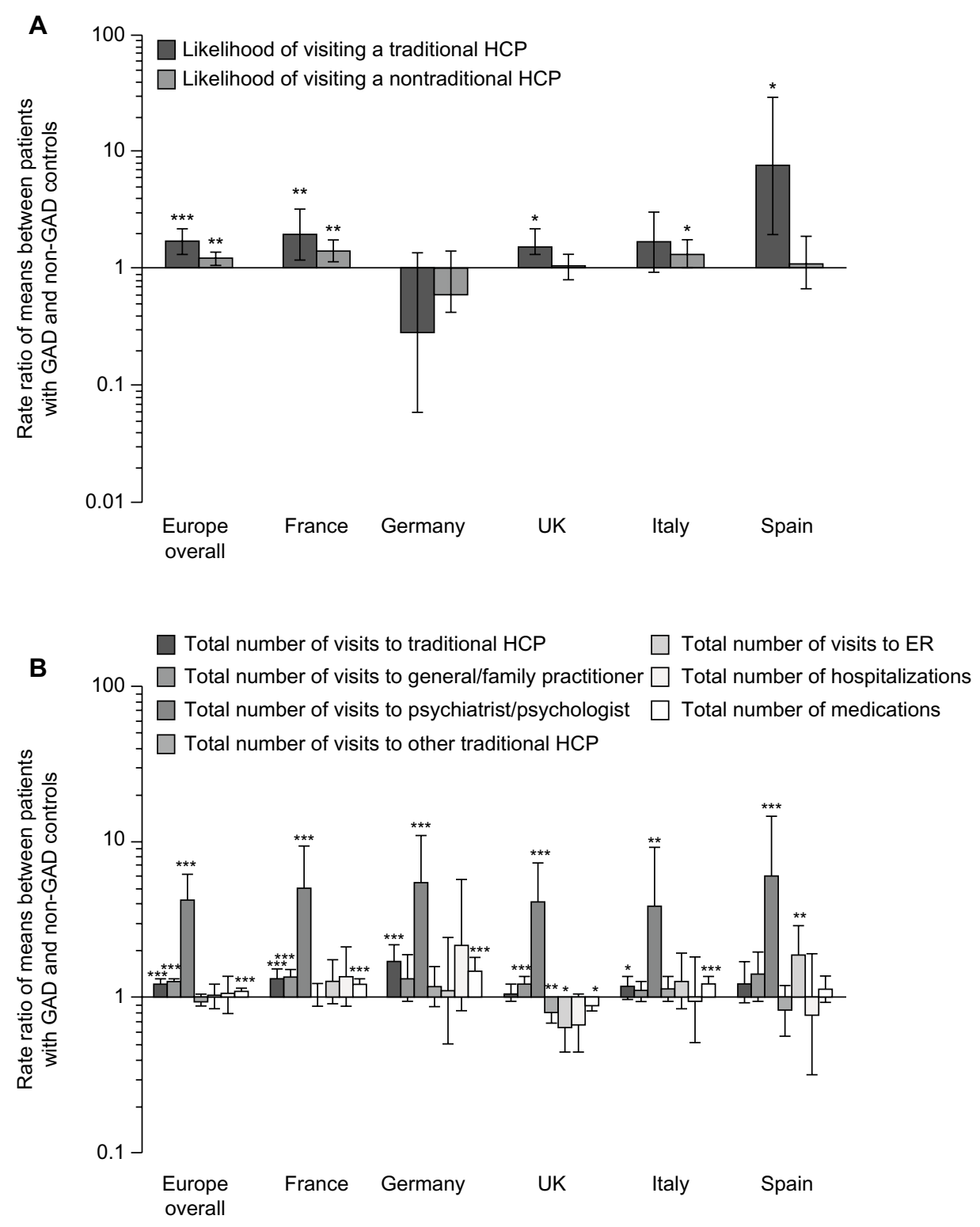

Figure 2 Difference in health care resource utilization in patients with GAD and non-GAD controls.

Notes: Data shown are for $(\mathbf{A})$ likelihood of visiting traditional and nontraditional health care providers and $(\mathbf{B})$ type of health care interaction. $* P<0.05$; $* * P<0.0$ I $* * * P<0.00$ I GAD patients versus non-GAD controls. Rate ratio $>$ I indicates the mean value for GAD patients is higher than for non-GAD controls; rate ratio $<$ I indicates the mean value for GAD patients is lower than for non-GAD controls. Europe overall refers to the five European countries included in this study. Abbreviations: ER, emergency room; GAD, generalized anxiety disorder; $\mathrm{HCP}$, health care provider.

\section{Discussion}

It has previously been debated whether GAD should be recognized as a specific health concern. ${ }^{25-27}$ Discussion of the significance and impact of GAD as a unique disease entity has been addressed by a number of studies investigating the personal and social health care burden of this disease..$^{13,15-20,28}$ These studies have suggested that GAD negatively impacts on activities of daily life and patients' HRQoL, and results in the possibility of decreased lifetime work productivity, thereby having a significant economic burden. However, despite the prevalence of this disorder, there is relatively little published evidence estimating the economic and humanistic burden of illness in patients with GAD in Europe. GAD remains poorly recognized and inadequately treated. Clinical management problems encountered by physicians are often due to the complexity and highly comorbid nature of GAD. Some physicians may fail to recognize and treat the disorder, despite the range of effective treatment options available. ${ }^{29}$ The aim of this real-world evaluation was to investigate the demographics, disease characteristics, impact on HRQoL, work productivity, health care resource utilization, and cost burden for patients with GAD across five European countries. 
Table 2 Average direct and indirect costs per patient with GAD per year

\begin{tabular}{|c|c|c|c|}
\hline Cost cor & $\begin{array}{l}\text { GAD } \\
\text { patients } \\
n=3,669\end{array}$ & $\begin{array}{l}\text { Non-GAD } \\
\text { controls } \\
n=3,669\end{array}$ & $\begin{array}{l}\text { Mean difference } \\
(95 \% \mathrm{CI})\end{array}$ \\
\hline \multicolumn{4}{|l|}{ Direct costs $(€)$} \\
\hline Medication & 41.79 & 2.95 & $38.84(35.70-41.98)$ \\
\hline $\begin{array}{l}\text { Emergency } \\
\text { room visits }\end{array}$ & 61.67 & 32.90 & 28.77 (19.53-38.02) \\
\hline Hospitalizations & 619.09 & 235.31 & $383.78(266.80-500.80)$ \\
\hline $\begin{array}{l}\text { General/family } \\
\text { practitioner visits }\end{array}$ & 159.19 & 90.19 & $69.00(61.90-76.12)$ \\
\hline $\begin{array}{l}\text { Psychologist/ } \\
\text { psychiatrist visits }\end{array}$ & 164.97 & 25.97 & $139.00(\mid 20.60-157.40)$ \\
\hline Total direct costs & I,046.7I & 387.32 & $659.39(534.30-784.50)$ \\
\hline \multicolumn{4}{|l|}{ Indirect costs $(€)$} \\
\hline Absenteeism & $1,510.30$ & 590.27 & $920.03(7|I-I| 29)$, \\
\hline Presenteeism & $2,751.80$ & $\mathrm{I}, 463.50$ & I,288.30 (I,079-I,498) \\
\hline Total indirect costs & $4,262.10$ & $2,053.77$ & $2,208.33(1,900-2,517)$ \\
\hline Total costs $(€)$ & $5,308.81$ & $2,441.09$ & $2,867.72(2,526-3,210)$ \\
\hline
\end{tabular}

Note: Data from France, Germany, Italy, Spain, and the UK.

Abbreviations: $\mathrm{Cl}$, confidence interval; GAD, generalized anxiety disorder.

The results revealed that patients with GAD had more comorbidities and were more likely to smoke but less likely to be employed, use alcohol, and take exercise. The increased number of comorbidities is consistent with the findings of previous epidemiological analyses, which have reported high rates of comorbidities in patients with GAD. ${ }^{12,30}$ In this study, patients with GAD were less likely to use alcohol compared with non-GAD controls, although previous studies have reported alcohol dependency as common. ${ }^{12,30,31}$ However, one of the limitations of this study is that all data are from a selfreported Internet survey, and patients may have been reticent to reveal the extent of their alcohol use.

The presence of GAD adversely affected patients' functioning and daily life, and was associated with significantly lower HRQoL scores and utilities versus non-GAD controls. Overall, European patients with GAD were found to have significantly worse HRQoL, with lower Short Form-12 Health Survey Version $2,{ }^{22}$ and particularly MCS, scores. Additionally, as GAD severity increased, the gap between patients and controls widened considerably. These findings are consistent with previous reports that the mean utility scores for HRQoL assessments among patients with GAD were similar to those for patients who were 20 years older, ${ }^{16}$ or that patients with GAD had significantly impaired HRQoL compared with the general population, and that GAD relapse is associated with a further deterioration of HRQoL. ${ }^{18,28}$

Lost productivity due to absence from work is reported to be the most costly consequence of GAD. ${ }^{30,32}$ This evaluation highlights a substantial burden of illness for patients with
GAD in terms of their work impairment, and confirms that work impairment metrics in Europe overall are significantly higher for patients with GAD versus non-GAD controls: patients with GAD had significantly higher work absenteeism due to health reasons, more impairment while working, and more impairment during daily activities.

In terms of resource use, GAD imposes significant costs on individuals, health care systems, and society in general. ${ }^{30}$ Our investigation also demonstrated the substantial burden of patients with GAD in terms of their additional resource use. Overall, patients in Europe with GAD were more likely to visit both traditional and nontraditional health care providers and had more medications compared with nonGAD controls. No significant differences between patients with GAD and non-GAD controls were observed for average number of emergency room visits or average number of hospitalizations. Within-country analyses generally demonstrated similar results to those obtained for Europe overall, although in the UK, patients with GAD received a lower number of medications than non-GAD controls. In Germany, while there were no significant differences in the likelihood of visiting traditional and nontraditional health care providers, the actual total number of visits to a traditional health care provider was significantly higher in patients with GAD versus non-GAD controls. This suggests that there may be a degree of variability between patients in the number of visits to a traditional health care provider.

As the evidence mounts for GAD causing significant productivity loss and additional resource use, substantial costs for both employers and society are to be expected. Indeed, the overall economic burden associated with this disease has been growing steadily. In the USA in 1990, the annual cost of anxiety disorders was $\$ 42-47$ billion, including prescription drugs, medical/surgical services, and indirect costs. ${ }^{33}$ The results of the cost analysis in this study illustrate the considerable financial impact of GAD. Interestingly, direct costs in Europe were not substantially different between patients with GAD and non-GAD controls and most of the GAD costs were indirect costs as a result of work impairment (both absenteeism and presenteeism) suffered by patients. Costs were particularly high in Germany due to higher salaries and thus greater expense incurred with missed work. As expected, the economic impact of GAD increased substantially as severity increased. Nevertheless, these results suggest that improvements in HRQoL could yield a considerable decrease in total costs for GAD in Europe, driven mainly by a reduction of indirect costs.

The results of this investigation support the rationale that GAD presents a considerable burden across Europe in terms of 


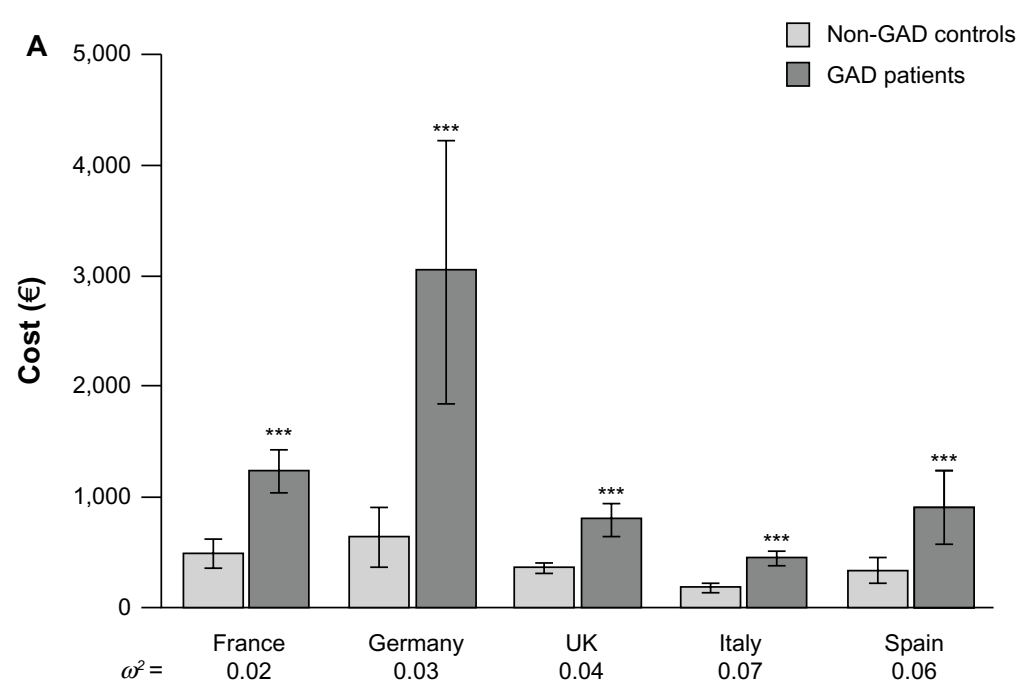

B

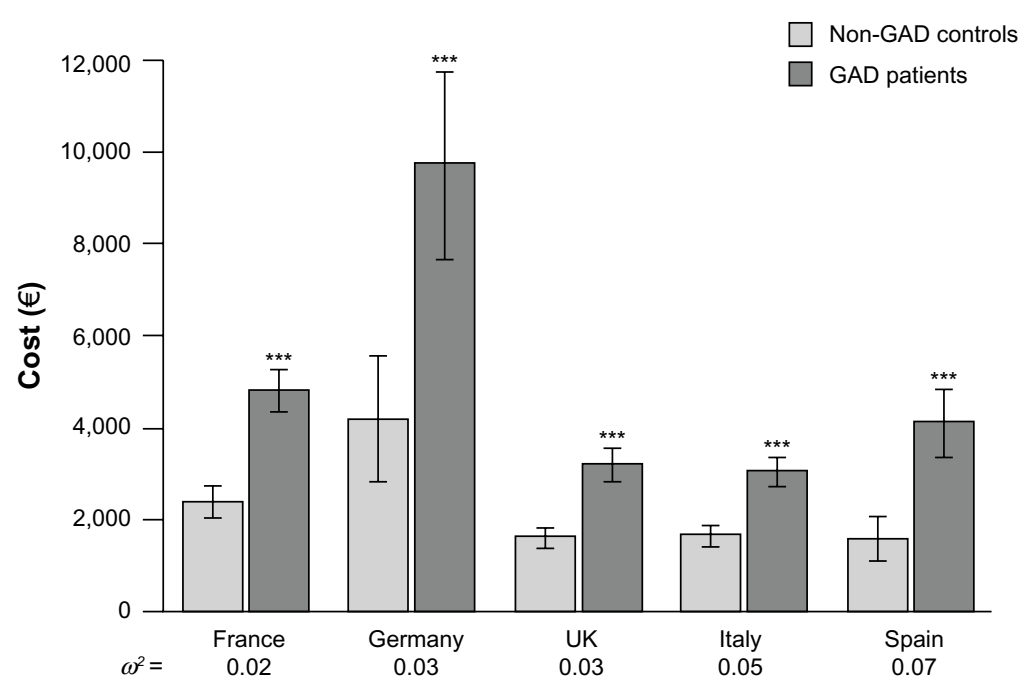

Figure 3 Average direct and indirect costs per patient with GAD per year.

Notes: Data from across France, Germany, Italy, Spain, and the UK (mean difference between patients with GAD and non-GAD controls) showing (A) direct costs and (B) indirect costs. $* * * P<0.001 \mathrm{GAD}$ patients versus non-GAD controls.

Abbreviation: GAD, generalized anxiety disorder.

work impairment and additional resource use. These findings are consistent with previous studies that have indicated a considerable personal and societal health care burden in Europe. ${ }^{19,20,30}$ However, to our knowledge, and in contrast with previous analyses, this study is the first to provide such a comprehensive analysis of "real-world" data on the burden of GAD across Europe. Indeed, the demonstrated impact of GAD on work productivity is especially pertinent in view of the high unemployment rates being experienced in Europe due to the recent recession. ${ }^{34}$ In this type of competitive environment, employees face increased pressure to be productive at work but must be well enough to do so.

The primary limitation of this evaluation was that the data were from a self-reported Internet survey, making them subject to reporting bias. As a result, it may be that some participants suffering from similar disorders, such as generalized social anxiety disorder, may have been included. It should also be noted that the data were cross-sectional, so it cannot be determined whether GAD was causally related to any of the health outcomes observed here. Indeed, it is possible that poorer outcomes could cause GAD, the relationships could be bidirectional (ie, GAD causes outcomes while outcomes also cause GAD), or a third variable may cause both. Another consideration was that the Internet-based questionnaire used may have been subject to sample bias because, by necessity, participants were required to have the knowledge and ability to access the Internet and also voluntarily chose to take part. A further limitation was that data were taken from only five countries in Europe, because that 


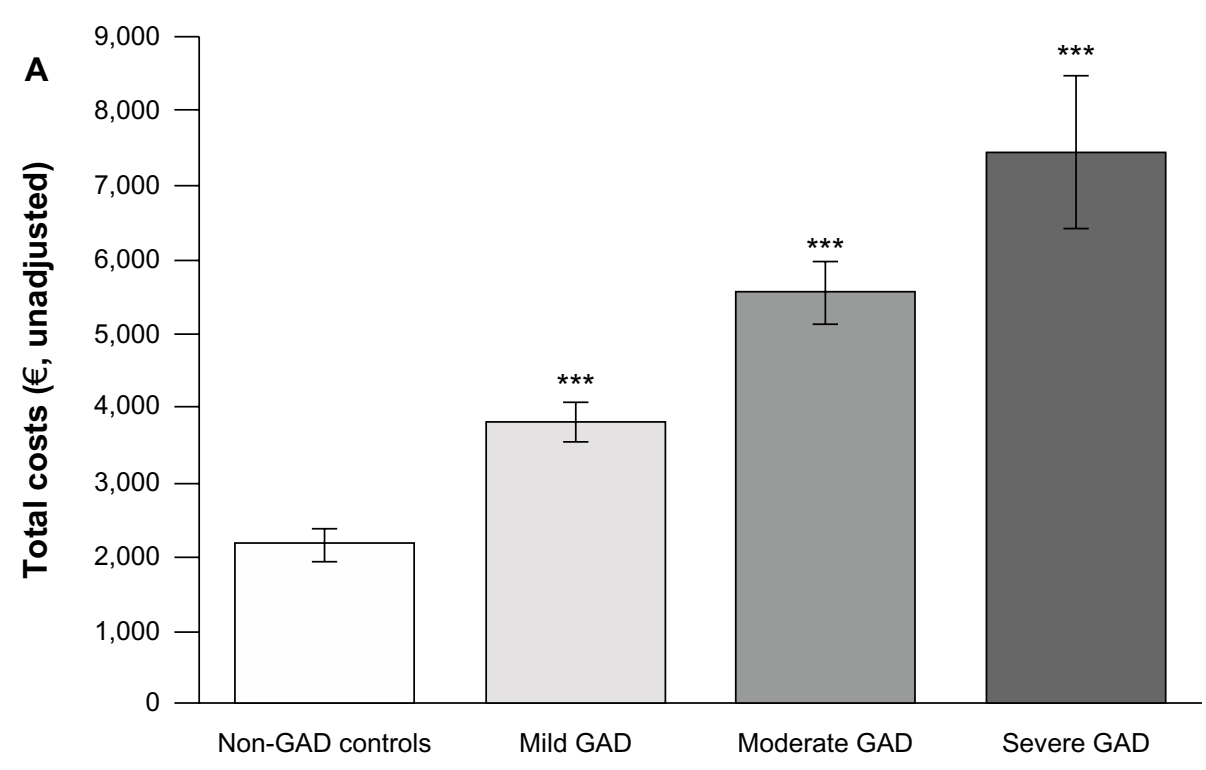

$\omega^{2}=0.05$

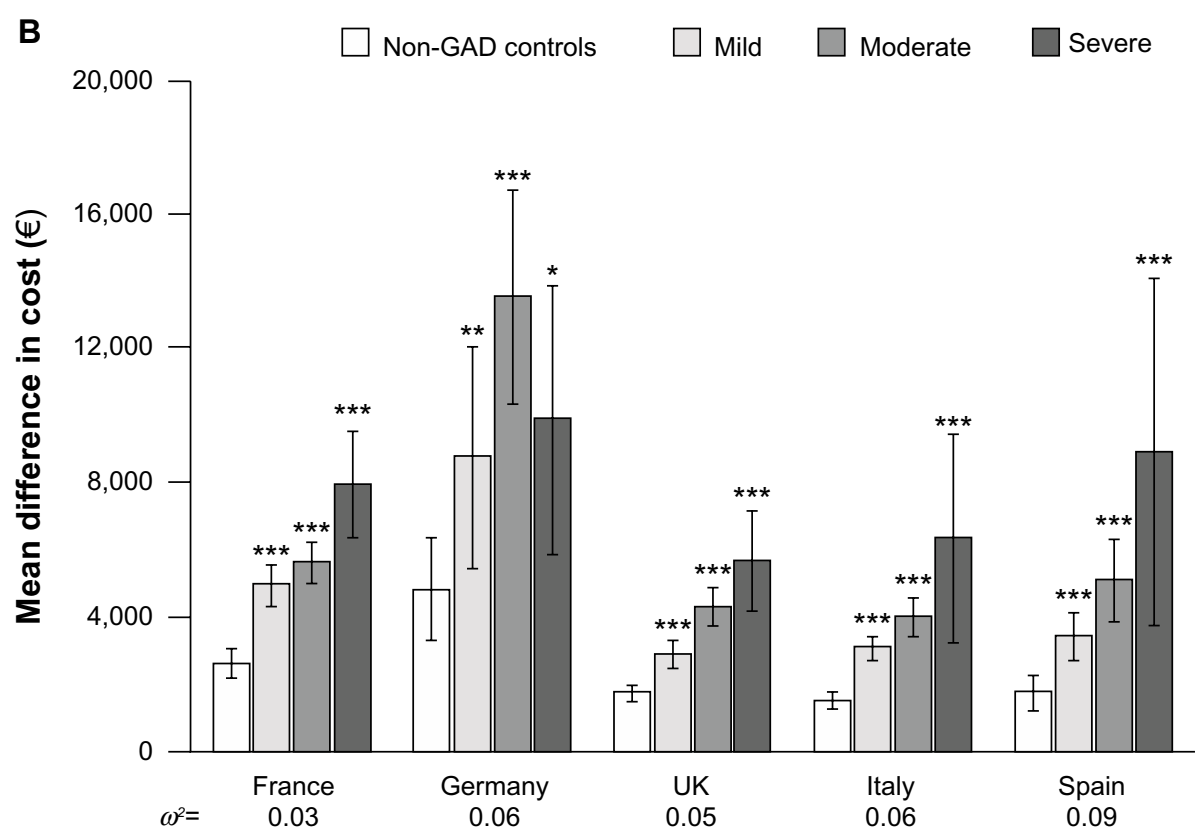

Figure 4 Health care costs of GAD by GAD severity.

Notes: Data show (A) average total costs per patient with GAD per year by GAD severity across five European countries (France, Germany, Italy, Spain, and the UK) and (B) mean difference in total costs for patients with GAD versus non-GAD controls by GAD severity within the five European countries. $* P<0.05 ; * * P<0.01$; $* * * P<0.001$ GAD patients versus non-GAD controls.

Abbreviation: GAD, generalized anxiety disorder.

Table 3 Decreases in estimated costs associated with improvements in HRQoL per patient per year

\begin{tabular}{|c|c|c|}
\hline \multirow[t]{2}{*}{$\begin{array}{l}\text { Cost } \\
\text { component }\end{array}$} & \multicolumn{2}{|c|}{$\begin{array}{l}\text { Estimated cost change per } 0.0 \mathrm{I} \text { increase } \\
\text { in utility score }(€[95 \% \mathrm{Cl}])\end{array}$} \\
\hline & GAD patients & Non-GAD control \\
\hline Direct costs & $-53.34(-65.07,-41.60)$ & $-22.47(-26.04,-18.91)$ \\
\hline Indirect costs & $-118.02(-144.08,-91.96)$ & $-68.74(-81.38,-56.1 \mathrm{I})$ \\
\hline Total costs & $-171.36(-200.49,-142.23)$ & $-91.21(-104.64,-77.79)$ \\
\hline
\end{tabular}

Abbreviations: $\mathrm{Cl}$, confidence interval; $\mathrm{GAD}$, generalized anxiety disorder; HRQoL, health-related quality of life. was the extent of the data available from the National Health and Wellness Survey. ${ }^{21}$ Data from other European countries not included in the survey may have differed, thus reducing the generalizability of these results.

\section{Conclusion}

This real-world evaluation shows that GAD represents a considerable economic and humanistic burden in Europe that increases with GAD severity. Consequently, attention 
needs to be focused on improving diagnosis and treatment options in order to help reduce the burden of GAD on both the individual and society as a whole.

\section{Acknowledgments}

We gratefully acknowledge the patients who participated in this study for their invaluable contribution. We thank Shaloo Gupta of Kantar Health, who provided analytical support. We thank Varinia Munoz of Complete Medical Communications, who provided medical writing support funded by AstraZeneca. AstraZeneca purchased access to the European National Health and Wellness Survey data and funded the analysis.

\section{Author contributions}

All authors were involved in the analysis and interpretation of data. All authors contributed to and approved the final manuscript.

\section{Disclosure}

MDB is a full-time employee of Kantar Health. ST, KJ, and JCL were employees of AstraZeneca at the time this analysis was conceived, undertaken, and completed. AstraZeneca provided support for the data collection and project management for the manuscript. Medical writing support was also funded by AstraZeneca.

\section{References}

1. American Psychiatric Association. Diagnostic and Statistical Manual of Mental Disorders, Fourth Edition, Text Revision. Washington, DC American Psychiatric Association; 2000.

2. Mendlowicz MV, Stein MB. Quality of life in individuals with anxiety disorders. Am J Psychiatry. 2000;157(5):669-682.

3. Vesga-Lopez O, Schneier FR, Wang S, et al. Gender differences in generalized anxiety disorder: results from the National Epidemiologic Survey on Alcohol and Related Conditions (NESARC). J Clin Psychiatry. 2008;69(10):1606-1616.

4. Wittchen HU, Zhao S, Kessler RC, Eaton WW. DSM-III-R generalized anxiety disorder in the National Comorbidity Survey. Arch Gen Psychiatry. 1994;51(5):355-364.

5. Culpepper L. Generalized anxiety disorder and medical illness. J Clin Psychiatry. 2009;70 Suppl 2:20-24.

6. Moffitt TE, Harrington H, Caspi A, et al. Depression and generalized anxiety disorder: cumulative and sequential comorbidity in a birth cohort followed prospectively to age 32 years. Arch Gen Psychiatry. 2007;64(6): 651-660.

7. Newman MG, Przeworski A, Fisher AJ, Borkovec TD. Diagnostic comorbidity in adults with generalized anxiety disorder: impact of comorbidity on psychotherapy outcome and impact of psychotherapy on comorbid diagnoses. Behav Ther. 2010;41(1):59-72.

8. Schoevers RA, Beekman AT, Deeg DJ, Jonker C, van Tilberg W. Comorbidity and risk-patterns of depression, generalised anxiety disorder and mixed anxiety-depression in later life: results from the AMSTEL study. Int J Geriatr Psychiatry. 2003;18(11):994-1001.

9. Simon NM. Generalized anxiety disorder and psychiatric comorbidities such as depression, bipolar disorder, and substance abuse. $J$ Clin Psychiatry. 2009;70 Supp1 2:10-14.

10. Munk-Jorgensen P, Allgulander C, Dahl AA, et al. Prevalence of generalized anxiety disorder in general practice in Denmark, Finland, Norway, and Sweden. Psychiatr Serv. 2006;57(12):1738-1744.
11. Weiller E, Bisserbe JC, Maier W, Lecrubier Y. Prevalence and recognition of anxiety syndromes in five European primary care settings. A report from the WHO study on psychological problems in general health care. Br J Psychiatry Suppl. 1998;34:18-23.

12. Lieb R, Becker E, Altamura C. The epidemiology of generalized anxiety disorder in Europe. Eur Neuropsychopharmacol. 2005;15(4):445-452.

13. Wittchen HU, Kessler RC, Beesdo K, Krause P, Hofler M, Hoyer J. Generalized anxiety and depression in primary care: prevalence, recognition, and management. J Clin Psychiatry. 2002;63 Suppl 8:24-34.

14. Bandelow B, Zohar J, Hollander E, Kasper S, Moller HJ. World Federation of Societies of Biological Psychiatry (WFSBP) guidelines for the pharmacological treatment of anxiety, obsessive-compulsive and post-traumatic stress disorders - first revision. World J Biol Psychiatry. 2008;9(4):248-312.

15. Andlin-Sobocki P, Wittchen HU. Cost of anxiety disorders in Europe. Eur J Neurol. 2005;12 Suppl 1:39-44.

16. Bereza BG, Machado M, Einarson TR. Systematic review and quality assessment of economic evaluations and quality-of-life studies related to generalized anxiety disorder. Clin Ther. 2009;31(6):1279-1308.

17. Hoffman DL, Mychaskiw M. The burden of generalized anxiety disorder in Germany. German Journal of Psychiatry. 2008;11:159-167.

18. Hoffman DL, Dukes EM, Wittchen HU. Human and economic burden of generalized anxiety disorder. Depress Anxiety. 2008;25(1):72-90.

19. Souetre E, Lozet H, Cimarosti I, et al. Cost of anxiety disorders: impact of comorbidity. J Psychosom Res. 1994;38 Suppl 1:151-160.

20. Surtees PG, Wainwright NW, Khaw KT, Day NE. Functional health status, chronic medical conditions and disorders of mood. $\mathrm{Br} \mathrm{J}$ Psychiatry. 2003;183:299-303.

21. Langley P, Muller-Schwerfe G, Nicolaou A, Liedgens H, Pergolizzi J, Varrassi G. The impact of pain on labor force participation, absenteeism and presenteeism in the European Union. J Med Econ. 2010;13(4):662-672.

22. Ware JE, Kosinski M, Turner-Bowker DM, Gandek B: How to score version 2 of the SF-12 health survey (with supplement documenting version 1). Lincoln: QualityMetric Incorporated; 2002.

23. Reilly MC, Zbrozek AS, Dukes EM. The validity and reproducibility of a work productivity and activity impairment instrument. Pharmacoeconomics. 1993;4(5):353-365.

24. Brazier JE, Roberts J. The estimation of a preference-based measure of health from the SF-12. Med Care. 2004;11:851-859.

25. Breier A, Charney DS, Heninger GR. The diagnostic validity of anxiety disorders and their relationship to depressive illness. Am J Psychiatry. 1985;142(7):787-797.

26. Massion AO, Warshaw MG, Keller MB. Quality of life and psychiatric morbidity in panic disorder and generalized anxiety disorder. $\mathrm{Am} \mathrm{J}$ Psychiatry. 1993;150(4):600-607.

27. Kessler RC, Andrade LH, Bijl RV, Offord DR, Demler OV, Stein DJ. The effects of co-morbidity on the onset and persistence of generalized anxiety disorder in the ICPE surveys. International Consortium in Psychiatric Epidemiology. Psychol Med. 2002;32(7):1213-1225.

28. Allgulander C, Jorgensen T, Wade A, et al. Health-related quality of life (HRQoL) among patients with generalised anxiety disorder: evaluation conducted alongside an escitalopram relapse prevention trial. Curr Med Res Opin. 2007;23(10):2543-2549.

29. Parmentier H, Garcia-Campayo J, Prieto R. Comprehensive review of generalized anxiety disorder in primary care in Europe. Curr Med Res Opin. 2013;29(4):355-367.

30. Wittchen HU. Generalized anxiety disorder: prevalence, burden, and cost to society. Depress Anxiety. 2002;16(4):162-171.

31. Weissman M. Anxiety and alcoholism. J Clin Psychiatry. 1988;49 Suppl:17-19.

32. Rice DP, Miller LS. Health economics and cost implications of anxiety and other mental disorders in the United States. Br J Psychiatry Suppl. 1998;34:4-9.

33. Greenberg PE, Sisitsky T, Kessler RC, et al. The economic burden of anxiety disorders in the 1990s. J Clin Psychiatry. 1999;60(7):427-435.

34. newseconomics.com. Unemployment in Europe: it's not just Spain. Available from: http://www.newseconomics.com/2010/01/unemploymentin-europe-its-bad-all-over.html. Accessed March 9, 2011. 


\section{Supplementary tables}

Table SI Patient demographics and disease characteristics within five European countries

\begin{tabular}{|c|c|c|c|c|c|c|}
\hline \multirow[t]{2}{*}{ Demographics } & \multicolumn{3}{|l|}{ France } & \multicolumn{3}{|l|}{ Germany } \\
\hline & $\begin{array}{l}\text { GAD } \\
n=|, 4| 8\end{array}$ & $\begin{array}{l}\text { Non-GAD } \\
\text { controls } \\
n=1,217\end{array}$ & $\begin{array}{l}\text { Mean } \\
\text { difference } \\
(95 \% \mathrm{Cl})\end{array}$ & $\begin{array}{l}\text { GAD } \\
n=218\end{array}$ & $\begin{array}{l}\text { Non-GAD } \\
\text { controls } \\
n=216\end{array}$ & $\begin{array}{l}\text { Mean difference } \\
(95 \% \mathrm{Cl})\end{array}$ \\
\hline Mean (SD) age, years & $45.6(13.2)$ & $42.4(12.1)$ & $\begin{array}{l}-3.18 \\
(-4.15,-2.20)\end{array}$ & $44.3(13.1)$ & $43.7(12.7)$ & $\begin{array}{l}-0.67 \\
(-3.10,1.77)\end{array}$ \\
\hline Male, \% & 26.0 & 25.1 & - & 41.7 & 41.7 & - \\
\hline Married, \% & 43.1 & 41.7 & - & 33.5 & 43.1 & - \\
\hline Employment status, \% & & & & & & - \\
\hline Employed & 50.9 & 61.6 & - & 45.9 & 49.1 & \\
\hline Retired & 16.2 & 2.8 & & 18.4 & 14.8 & \\
\hline On disability & 6.8 & 7.1 & & 7.3 & 5.1 & \\
\hline Other & 26.2 & 28.5 & & 28.4 & 31.0 & \\
\hline Alcohol user, \% & 74.3 & 75.8 & - & 71.6 & 77.8 & - \\
\hline Current smoker, \% & 39.6 & 35.1 & - & 41.7 & 39.8 & - \\
\hline $\begin{array}{l}\text { Mean (SD) days exercised } \\
\text { per month }\end{array}$ & $5.2(7.6)$ & $5.5(7.8)$ & $\begin{array}{l}0.26 \\
(-0.33,0.85)\end{array}$ & $4.3(6.6)$ & $5.3(7.2)$ & $\begin{array}{l}1.04 \\
(-0.26,2.34)\end{array}$ \\
\hline Comorbidity count & $9.9(4.4)$ & $4.3(3.8)$ & $\begin{array}{l}-5.53 \\
(-5.84,-5.21)\end{array}$ & $14.6(7.9)$ & $5.5(4.4)$ & $\begin{array}{l}-9.06 \\
(-10.27,-7.84)\end{array}$ \\
\hline
\end{tabular}

Note: Control group had no specific GAD diagnosis (self-report) but could have reported another anxiety disorder (eg, social anxiety disorder, panic disorder).

Abbreviations: $\mathrm{Cl}$, confidence interval; GAD, generalized anxiety disorder; $\mathrm{SD}$, standard deviation.

Table S2 HRQoL scores within five European countries

\begin{tabular}{|c|c|c|c|c|c|c|c|c|}
\hline \multirow[t]{2}{*}{ HRQoL score } & \multicolumn{3}{|l|}{ France } & \multicolumn{3}{|l|}{ Germany } & \multicolumn{2}{|l|}{ UK } \\
\hline & $\begin{array}{l}\text { GAD } \\
n=|, 4| 8\end{array}$ & $\begin{array}{l}\text { Non-GAD } \\
\text { controls } \\
n=1,217\end{array}$ & $\begin{array}{l}\text { Mean difference } \\
(95 \% \mathrm{CI})\end{array}$ & $\begin{array}{l}\text { GAD } \\
n=218\end{array}$ & $\begin{array}{l}\text { Non-GAD } \\
\text { controls } \\
n=216\end{array}$ & $\begin{array}{l}\text { Mean difference } \\
(95 \% \mathrm{CI})\end{array}$ & $\begin{array}{l}\text { GAD } \\
n=1,055\end{array}$ & $\begin{array}{l}\text { Non-GAD } \\
\text { controls } \\
n=1,245\end{array}$ \\
\hline $\begin{array}{l}\text { PCS score, } \\
\text { mean (SD) }\end{array}$ & 46.5 (II.I) & $49.9(10.2)$ & $3.38(2.55,4.20)$ & $42.4(11.2)$ & $47.3(10.9)$ & $4.88(2.79,6.96)$ & $43.9(13.3)$ & $45.5(12.6)$ \\
\hline $\begin{array}{l}\text { MCS score, }{ }^{22} \\
\text { mean (SD) }\end{array}$ & $33.5(10.1)$ & $44.6(10.6)$ & $11.12(10.33,11.91)$ & $32.3(10.9)$ & $46.5(12.0)$ & $14.16(12.00,16.32)$ & $35.2(11.7)$ & $46.4(11.3)$ \\
\hline $\begin{array}{l}\text { Health utilities } \\
\text { score, }{ }^{24} \\
\text { mean }(S D)\end{array}$ & $0.6(0.1)$ & $0.7(0.1)$ & $0.11(0.10,0.12)$ & $0.6(0.1)$ & $0.7(0.1)$ & $0.13(0.11,0.15)$ & $0.6(0.1)$ & $0.7(0.2)$ \\
\hline
\end{tabular}


Table SI (Continued)

\begin{tabular}{|c|c|c|c|c|c|c|c|c|}
\hline \multicolumn{3}{|l|}{ UK } & \multicolumn{3}{|l|}{ Italy } & \multicolumn{3}{|l|}{ Spain } \\
\hline $\begin{array}{l}\text { GAD } \\
n=I, 055\end{array}$ & $\begin{array}{l}\text { Non-GAD } \\
\text { contsrol } \\
n=I, 245\end{array}$ & $\begin{array}{l}\text { Mean } \\
\text { difference } \\
(95 \% \mathrm{Cl})\end{array}$ & $\begin{array}{l}\text { GAD } \\
n=730\end{array}$ & $\begin{array}{l}\text { Non-GAD } \\
\text { controls } \\
\mathrm{n}=739\end{array}$ & $\begin{array}{l}\text { Mean } \\
\text { difference } \\
(95 \% \mathrm{Cl})\end{array}$ & $\begin{array}{l}\text { GAD } \\
n=248\end{array}$ & $\begin{array}{l}\text { Non-GAD } \\
\text { controls } \\
\mathrm{n}=\mathbf{2 5 2}\end{array}$ & $\begin{array}{l}\text { Mean } \\
\text { difference } \\
(95 \% \mathrm{Cl})\end{array}$ \\
\hline $46.9(13.5)$ & $48.8(13.6)$ & $\begin{array}{l}1.95 \\
(0.84,3.06)\end{array}$ & $48.7(13.8)$ & $47.2(14.1)$ & $\begin{array}{l}-1.44 \\
(-2.87,-0.02)\end{array}$ & $45.7(13.2)$ & $44.0(13.9)$ & $\begin{array}{l}-1.75 \\
(-4.13,0.63)\end{array}$ \\
\hline 38.3 & 38.3 & - & 40.1 & 38.3 & - & 35.5 & 34.5 & - \\
\hline 46.8 & 54.6 & $\begin{array}{l}- \\
-\end{array}$ & 59.2 & 56.2 & $\begin{array}{l}- \\
-\end{array}$ & 52.8 & 49.6 & $\begin{array}{l}- \\
-\end{array}$ \\
\hline 48.0 & 56.8 & & 65.1 & 65.8 & & 68.2 & 57.9 & \\
\hline 17.1 & 13.7 & & 18.1 & 13.8 & & 11.3 & 11.5 & \\
\hline 16.6 & 14.1 & & 0.1 & 0.0 & & 3.6 & 4.8 & \\
\hline 18.4 & 15.3 & & 16.7 & 20.4 & & 16.9 & 25.8 & \\
\hline 80.5 & 84.2 & - & 70.1 & 68.3 & - & 64.1 & 73.8 & - \\
\hline 33.7 & 26.2 & - & 34.3 & 27.6 & - & 44.4 & 32.5 & - \\
\hline $5.5(7.7)$ & $6.0(8.3)$ & $\begin{array}{l}0.47 \\
(-0.19,1.12)\end{array}$ & $5.6(7.6)$ & $5.3(7.5)$ & $\begin{array}{l}-0.32 \\
(-1.1,0.46)\end{array}$ & $5.5(8.0)$ & $7.4(8.8)$ & $\begin{array}{l}1.92 \\
(0.45,3.40)\end{array}$ \\
\hline II .4 (5.0) & $5.8(4.4)$ & $\begin{array}{l}-5.63 \\
(-6.01,-5.24)\end{array}$ & $10.5(6.3)$ & $4.6(4.2)$ & $\begin{array}{l}-5.9 \\
(-6.44,-5.35)\end{array}$ & $9.4(4.7)$ & $4.2(3.4)$ & $\begin{array}{l}-5.26 \\
(-5.98,-4.54)\end{array}$ \\
\hline
\end{tabular}

Table S2 (Continued)

\begin{tabular}{|c|c|c|c|c|c|c|}
\hline \multirow[b]{2}{*}{$\begin{array}{l}\text { Mean difference } \\
(95 \% \mathrm{Cl})\end{array}$} & \multicolumn{3}{|l|}{ Italy } & \multicolumn{3}{|l|}{ Spain } \\
\hline & $\begin{array}{l}\text { GAD } \\
n=730\end{array}$ & $\begin{array}{l}\text { Non-GAD } \\
\text { controls } \\
\mathrm{n}=739\end{array}$ & $\begin{array}{l}\text { Mean difference } \\
(95 \% \mathrm{Cl})\end{array}$ & $\begin{array}{l}\text { GAD } \\
n=248\end{array}$ & $\begin{array}{l}\text { Non-GAD } \\
\text { controls } \\
\mathrm{n}=\mathbf{2 5 2}\end{array}$ & $\begin{array}{l}\text { Mean difference } \\
(95 \% \mathrm{Cl})\end{array}$ \\
\hline $1.62(0.55,2.68)$ & $47.5(9.5)$ & $49.7(8.7)$ & $2.21(1.28,3.14)$ & $45.0(11.1)$ & $49.3(8.7)$ & $4.34(2.59,6.09)$ \\
\hline $11.17(10.23,12.12)$ & $36.1(9.3)$ & $44.2(10.1)$ & $8.05(7.06,9.05)$ & $40.1(9.9)$ & $48.9(9.5)$ & $8.8 \mathrm{I}(7.10,10.5 \mathrm{I})$ \\
\hline $0.11(0.09,0.12)$ & $0.6(0.1)$ & $0.7(0.1)$ & $0.07(0.06,0.08)$ & $0.6(0.1)$ & $0.8(0.1)$ & $0.12(0.10,0.14)$ \\
\hline
\end{tabular}

\section{Publish your work in this journal}

ClinicoEconomics \& Outcomes Research is an international, peerreviewed open-access journal focusing on Health Technology Assessment, Pharmacoeconomics and Outcomes Research in the areas of diagnosis, medical devices, and clinical, surgical and pharmacological intervention. The economic impact of health policy and health systems organization also constitute important areas of coverage. The manuscript management system is completely online and includes a very quick and fair peer-review system, which is all easy to use. Visit http://www.dovepress.com/testimonials.php to read real quotes from published authors. 